\title{
Exploration on Optimization of College Students' Employment Guidance Course From the Perspective of MOOC
}

\author{
Xiaohe $\mathrm{XU}^{1, \mathrm{a}}$, Yunchang $\mathrm{ZHAO}^{2, \mathrm{~b}}$, Guiyu Zhao ${ }^{3, \mathrm{c}}$ \\ ${ }^{1}$ College of Life Science, Jilin Agricultural University, Changchun, 130118, China \\ ${ }^{2}$ College of Foreign Languages, Jilin Agricultural University, Changchun, 130118, China \\ ${ }^{3}$ college of Economics and Management, Jilin Agricultural University, Changchun, \\ 130118, China

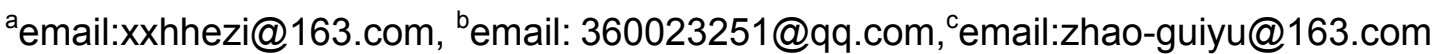

Keywords: Colleges and Universities, Employment Guidance, MOOC, Curriculum Optimization

\begin{abstract}
Massive Open Online Course (MOOC), as a new mode of education in the information era, has brought opportunities and challenges to the college employment guidance. Based on the analysis of employment guidance curriculum in colleges integrated with MOOC, this paper analyzes their current situation and problems and explores the advantages of the introduction of MOOC. Through fully stimulating students' interest in learning and improving teaching quality, the employment guidance education will become effective, professional and long-lasting to achieve the full, high-quality and satisfactory employment of graduates

As an important part of university education, employment guidance has positive effect on the reasonable and effective development and utilization of human resources. Under the background of economic slowdown, the employment situation of Chinese colleges and universities in 2015 is more severe. The number of college graduates across the country reached 7.49 milloin in 2015 , an increase of $22 \%$ over 2014. In the fierce competition in the employment, to find a satisfactory job becomes a common expectation of college graduates. In such circumstances, it is particularly necessary to provide students with professional, personalized employment guidance. With the development of network information technology, the learning style of college students has changed deeply. The teaching methods and teaching contents of the old employment guidance are slightly lagging behind the times and students and there are some shortcomings, for instance, single teaching mode, a lack of individualized instruction, students' passive learning, a lack of self and social cognition and the like. Since 2012, the massive open online course(MOOC) has been highly concerned by higher education at home and abroad. This paper analyzes the current situation of college students' employment guidance curriculum from the perspective of MOOC, and puts forward the way of applying it into practice, that is focusing on reflecting the leading role of the teachers and the students' main body consciousness, and further strengthening the construction of students' guidance curriculum, so that students can form a good sense of employment and improve their professional quality and comprehensive competitiveness in the fierce competition.
\end{abstract}

\section{First, The current situation of employment guidance curriculum in colleges and universities}

According to " Requirements on College Students Career Development and Employment Guidance Curriculum " issued by the Ministry of education, colleges and universities have established career development and career guidance system, employment guidance courses as public required course, set up the corresponding credits and time, set up career planning and career guidance courses, such as Career Awakening, Self Cognition, Exploration on Career Environment, Skills of Resume Writing and Interview, Situation and Policy of Employment, Starting a Business 
Independently and other topics. Teams of teachers of employment guidance courses have formed. In many colleges and universities, teachers of the employment guidance courses are mainly composed of the staff of Admission Office, Graduate Vocational Counsel Center, deputy secretaries of schools(departments) in charge of the work of the students, and full-time counselors.

(1) Too much attention to theoretical study of the content and the lack of professional practice.

The current teaching mode is still teacher-centered and focuses on the introduction of theoretical knowledge, ignoring practical training. At the same time, the proportion of practical teaching and case teaching is comparably low and teaching method is relatively simple, rarely referring to the new media and can't provide relevant practical training to meet social and companies' demands. Many colleges and universities are lack of specialized practice-teaching place such as employment counseling room, professional evaluation table, a mock interview room, employment data room and so on and don't provide opportunities like context simulation, sand table exercises, and role play etc. for students to improve their practical skills.

(2) The incomplete employment guidance and ignoring human job matching

The arrangement of employment guidance courses in most colleges and universities is to set career planning in the fresh year, and employment guidance courses in the second term of the junior year and in the first term of the senior year. Therefore, career guidance has not covered the four years. In the course of employment guidance, because of the limitations of time and place, "human-job matching" can seldom be achieved and there is no time to help students understand their professional values, interest, ability, personality characteristics and other objective conditions by means of questionnaires, all kinds of measurement scales, consulting and other ways. Because of the lack of employment guidance in the second and third year college students can't understand social various professional needs, employment status, and dynamic change of career development trend clearly and deeply and recognize the occupation accurately. And thus, they can't make choices calmly. Many colleges and universities just consider completing the employment guidance course teaching hours as the main task, and neglect the study on development plans, teaching contents, construction goals, effect evaluation and so on.

(3) The low degree of specialization of teachers and the poor teaching quality of employment guidance courses

Teachers of employment guidance courses in most colleges and universities are "temporary", not the professional team, some of which are responsible for the Marx doctrine, some are counselors, and more work in employment guidance centers. Because of their own stressful jobs, it is difficult for teachers to put much time and energy to study relevant theories and attend specialized business trainings, and most teachers of the employment guidance course go to work directly after graduation, so they don't have enough social experience to communicate with the employers and can learn the demands of enterprise and social for college students extensively and timely. In such circumstances, teaching contents will be slow to update, and the teaching quality of employment guidance courses can't be guaranteed. Meanwhile because of the lack teachers, in many colleges and universities the number of students attending employment guidance course is generally more than 100 people, some even more than 200 students and the large number of students attending the classes make it difficult in class organization.

(4) The lack of students' initiative and interaction between teachers and students

The traditional teaching mode is teacher-centered and teachers decide the teaching content and teaching method. Students in the class passively accept knowledge. They can't select what they learn, so they show little interest in participating in the class. Teachers in the classroom can't stimulate students' enthusiasm and initiative and also have less opportunity to interact with their 
students.

\section{Second, Advantages of the introduction of MOOC into teaching practice}

Massive open online course short for MOOC, was born in 2008, rising in 2012. With the rapid development of network information technology, and the change of demand of vocational education and learning style of human life, MOOC has risen rapidly. With the characteristics of low cost, being free of charge, rich In learning resources, strong teaching experience, and learning independently, MOOC is a kind of network teaching mode which is public-oriented and pays more attention to the teaching process. MOOC, a new educational model, can be based on the individual needs of learners, providing students with short time video and network resources, elite teachers' online presentation of the curriculum, continue to update learning resources, realize testing and feedback in real time, strengthen learning and improve the teaching effect.

(1) Abundant curriculum resources and improved interaction between teachers and students

MOOC adapts to the characteristics of the information age, and provides students with multi-angle, multi-level, quality resources of employment guidance. Students can learn employment guidance at home and abroad. Through MOOC platform, students' questions can be worked out immediately, and real-time monitoring of students' learning progress and their mentality and earning state can be realized. The improvement of teaching contents and method in time and effective interaction between teaching and learning, learning and learning can be achieved.

(2) Stimulating students' enthusiasm and initiative

In the MOOC, the study process is mainly based on the students' enthusiasm and initiative. In current employment guidance courses, students passively accept knowledge, while MOOC will inspire and guide students to learn and think, and their learning time and learning progress are also fully controlled by themselves. Students can choose courses with different depth and breadth according to their own needs and interests. The improvement of learning autonomy can help to reach students' learning potential and play an immeasurable role in learning efficiency.

(3) Promoting the improvement of teachers' teaching and professional skills

MOOC provides an effective and fair competition platform for employment guidance teachers. The teaching mode of MOOC decides that the students can choose the teachers and their courses, and outstanding teachers will be in hot pursuit, and otherwise, they will be eliminated. The positive competition among teachers is bound to bring about a substantial increase in teaching, and a large number of employment guidance resources will be emerging.

\section{Third, Ideas of the employment guidance course construction from the perspective of MOOC}

With the rapid development of information technology, the Internet provides people with a new way of information exchange. It has become a new trend to improve learning efficiency and learning effect in education research through new technology. It is of great significance to explore the integration of employment guidance and network technology from the perspective of MOOC to promote the quality and efficiency of employment guidance.

(1) Integrating teaching resources and improving the employment guidance curriculum system.

Take the advantages of MOOC to integrate teaching resources of employment guidance courses and provide multimedia videos concerning Employment Policies and Regulations, Workplace Etiquette, Interview Skills, Self Perception, Psychological Adjustment and the rest for students to study in order to change the situation of tense time. Combined with online feedback and problems students concerned about, organize outstanding teachers to develop the teaching syllabus of employment guidance based on MOOC, improve teaching resources, and establish a reasonable 
course system.

(2) Constructing MOOC platform of the employment guidance course with the participation of professional course teachers

Professional course teachers are familiar with the major characteristics, industry development situation, employment direction and work welfare and so on. In the MOOC platform, students' questions can be solved through micro lessons, micro chat and other ways of questions, ways to information interaction established and students can be helped students understand industry trends in this field, establish a reasonable career goals and career planning direction, realize "human job matching" which can integrate the students personality development with career development aspirations well together.

(3) Integrating social resources and achieving zero distance docking between students and job market

Make the most of MOOC platform to hire a business manager, the representatives of relevant industry human resources management as teachers and experts and students interact with each other to give guidelines to students from the perspective of the ability and quality employers demand of them. Through case analysis, situation simulation, group discussion and other methods, strengthen practice, highlight employment skills training, and enhance the pertinence and effectiveness of employment guidance.

(4) Combining traditional teaching and MOOC to launch full employment guidance.

For employment guidance curriculum "point type", the traditional teaching and MOOC teaching can be combined. Teachers can use the traditional teaching mode to understand the students' learning situation by face-to-face teaching in the first year; in the second and third year, MOOC will be adopted. Students can set their own learning goals, learning rhythm, and they can skip familiar knowledge and repeat what they are interested in or it is difficult to understand to improve learning efficiency. There is no limitation of their grade on the selection of courses so that the learning autonomy can be greatly enhanced; in the four year, to open the practical training, students can contact employers according to their interest to carry out graduation practice.

Make the employment guidance run through the whole college life dynamically, not static human job matching before graduation. Teachers should pay more attention to students' individual differences from the students' actual situation, "orient students", teach students in accordance with their aptitude by means of MOOC to provide personalized employment guidance for students of different majors, enhance students' professional quality, and improve the students' employment competitiveness.

\section{Acknowledgement}

In this paper, the research was sponsored by the Jilin Province Education Science "Twelfth Five Year Plan" 2014 year plan project: Research and Practice of Employment Guidance in Agricultural Colleges and Universities under the New Situation (Project Number: GH14154), and project: Comparative Study on the Development of Higher Education in China and in the United States (Project Number: GH12130)

\section{References}

[1] Wang Xiaogang. The Challenge and Thinking of the Educational Technology in the Era of MOOC (J). The Exploration of Education, 2014 (10): 48-50 
[2] Wang Wenli. Study on the development of MOOC and Its Influence on Higher Education [J].Teaching Study, 2013 (2): 53-57.

[3] Zhang Xiaofan. Expliration of the Mode of Employment Guidance Course in Colleges and Universities on the Basis of the Concept of MOOC, [J]. Chinese College Students' Employment, 2014 (18) 55-59.

[4] Fan Wenqiang. MOOC based on Relevance Theory and its Learning Support (J). Distance Education, 2012 (3): 32

[5] Li Peirong. The Employment Guidance and Strategies for College Graduates [J]. China Electronic Commerce 2013 (2).

[6] Lai Xiuming, Xu Xingzi. The Construction of Curriculum System of the Whole Employment Guidance in Colleges and Universities [J]. Journal of Xiaogan College, 2012 (4). 